\title{
Outcome of applying the European Society of Cardiology (ESC) 0/1-hour algorithm in patients with suspected myocardial infarction
}

Geneviève Gravel, MD*; Alain Miclette, MD, MBA*; Roxane Beaumont-Boileau, MD*; Julie CôtéLeclerc, MD*; Marcel Émond (), MD, MSc ${ }^{*}+\S \S$

\begin{abstract}
link: http://www.onlinejacc.org/content/74/ 4/483.abstract

Full citation: Twerenbold R, Costabel JP, Nestleberger $\mathrm{T}$, et al. Outcome of applying the ESC 0/1-hour algorithm in patients with suspected myocardial infarction. J Am Coll Cardiol 2019;74(4):483-94.

Article type: Diagnosis

Ratings: Methods - 3/5 Usefulness - 4/5
\end{abstract}

\section{INTRODUCTION}

\section{Background}

The European Society of Cardiology (ESC) recommends the 0/1-hour troponin dosage algorithm for rapid triage of patients with chest pain and suspected non-ST segment elevation myocardial infarction (MI).

\section{Objectives}

To determine safety, performance, and applicability of the 0/1-hour troponin triage algorithm when routinely applied in the emergency room

\section{METHODS}

\section{Design}

Prospective cohort study

\section{Setting}

Two university centres in Switzerland and Argentina

\section{Subjects}

Adult patients presenting with chest pain suggestive of MI; exclusion if STEMI diagnosis

\section{Intervention}

Standard assessment with history and physical examination plus determination of hs-cTnT at presentation and 1 hour after initial medical encounter. Management of patients was left to the discretion of the attending clinicians who were blinded to the study's outcomes.

\section{Outcomes}

Primary outcomes were triage performance when using the algorithm and 30-day rate of major adverse clinical events (MACE): cardiovascular death and MI. Secondary outcomes were feasibility and adherence to the triage algorithm and impact on emergency department (ED) resources use and length of stay.

\section{MAIN RESULTS}

The ESC 0/1-hour algorithm triaged $62 \%$ of patients towards "rule-out" category with a $0 \mathrm{~h}$ troponin $\mathrm{T}<5 \mathrm{ng} / \mathrm{L}$ or a $0 \mathrm{~h}<12 \mathrm{ng} / \mathrm{L}$ and $1 \mathrm{~h}$ change $<3 \mathrm{ng} / \mathrm{L}$. In the "rule-out" group, $88 \%$ of patients underwent

From the * Faculté de médecine, Département de médicine familiale et de médicine d'urgence, Université Laval, Québec, QC; ${ }^{\dagger} \mathrm{CHU}$ de Québec Université Laval, Québec, QC; ${ }^{\ddagger}$ Centre de recherche sur les soins et les services de première ligne de I'Université Laval (CERSSPL-UL), Québec, QC; and the ${ }^{\S}$ Centre d'excellence sur le vieillissement de Québec, Québec, QC.

Correspondence to: Dr. Marcel Émond, CHU de Québec-Hôpital de l’Enfant-Jésus, 1401, 18e rue, H-608, Québec, QC G1J 1Z4; Email: marcelemond1 @ me.com

(c) Canadian Association of Emergency Physicians 2020

CJEM 2020;22(3):299-300

DOI 10.1017/cem.2020.17 
outpatient management with a $0,1 \%$ occurrence of 30 -day MACE. The remaining patients (12\%) were treated as inpatients without justification provided, and $28 \%$ of these patients underwent revascularization therapy with $0,2 \%$ of 30 -day MACE. The overall 30 -day MACE in the "rule-out" category was $0,2 \%$ and does not include revascularization therapy. The algorithm was strictly adhered in $94 \%$ of patients' encounters with an average time between the blood draws of 65 minutes. The median time to discharge from the ED or transfer to a hospital ward was $2 \mathrm{hrs,}$ $30 \mathrm{~min}$.

\section{APPRAISAL}

\section{Strengths}

- Patient-oriented outcomes.

- Strong internal validity due to high adherence to algorithm.

- A complete patient follow-up for 30-day MACE - no lost to follow-up.

\section{Limitations}

- Data collection performed in EDs where 0-1 h protocol is already a standard of care and clinicians' awareness of the goal of the study sets a potential Hawthorne effect.

- Level and specialty of the clinicians performing the evaluation are unknown.

- Potential selection bias: recruitment method is unknown.

- Current algorithm cutoffs are only applicable to hs-cTnT assay (Elecsys 2010 high-sensitivity troponin T) not available in all EDs.

- No standardization of the "rule-out" patient cohort ED or post-ED management. Decision criteria to admit patients and to investigate as outpatients were not described. Early access to stratification testing and revascularization could have led to lower rates of 30-day MACE in this group.

- Revascularization was not considered as a primary outcome or an MACE. Interestingly, in the "rule-out" cohort, $4.4 \%$ of patients underwent revascularization following their ED visit.

\section{CONTEXT}

This study builds on the emerging literature showing the capacity of high-sensitivity troponin assays and short interval blood draws to reduce MI diagnosis delays and therefore allows for a more rapid initiation of adequate therapy. The ESC 0/1 hour algorithm appears to be safe and to effectively decrease time to ED discharge with a 30-day MACE rate of $0.1 \%$ in the outpatient cohort of 1,619 patients. Furthermore, a recent study showed the $0 / 1$ hour TnT protocol to be non-inferior to the standardized $0 / 3$ hours hs-cTnT protocol. ${ }^{1}$

\section{BOTTOM LINE}

The ESC 0/1 h hs-cTnT algorithm allows for safe early discrimination of patients presenting to the ED with chest pain and suspected NSTEMI in the presented cohort. $^{2}$ Nevertheless, $4.4 \%$ of patients in the "rule-out" low-risk group underwent revascularization procedure, which was not considered an MACE in this study. Moreover, this algorithm is not applicable to early presenters $(<3 \mathrm{hrs})$, patient with ongoing pain, or known renal insufficiency. Further studies acknowledging the safety with the different types of troponin assay are required for general applicability. ${ }^{3}$

Keywords: Cardiac disease, emergency medicine, evidence-based medicine

Competing interests: None declared.

\section{REFERENCES}

1. Chew DP, Lambrakis K, Blyth A, et al. A randomized trial of a 1-hour troponin T protocol in suspected acute coronary syndromes: the rapid assessment of possible acute coronary syndrome in the emergency department with high-sensitivity troponin T study (RAPID-TnT). Circulation 2019;140 (19):1543-56.

2. Roffi M, Patrono C, Collet JP, et al. 2015 ESC guidelines for the management of acute coronary syndromes in patients presenting without persistent ST-segment elevation: Task force for the management of acute coronary syndromes in patients presenting without persistent ST-segment elevation of the European Society of Cardiology (ESC). Eur Heart 7 2016;37 (3):267-315.

3. Levy PD, Mahler SA. Evaluating suspected acute MI in the emergency department: what is and what should never be. $\mathcal{F}$ Am Coll Cardiol 2019;74(4):495-7. 